ORIGINAL ARTICLE

\title{
Can strenuous leisure time physical activity prevent psychological complaints in a working population?
}

\author{
C M Bernaards, M P Jans, S G van den Heuvel, I J Hendriksen, I L Houtman, P M Bongers
}

Occup Environ Med 2006;63:10-16. doi: 10.1136/oem.2004.017541

See end of article for authors' affiliations

.....................

Correspondence to:

$\operatorname{Dr} C M$ Bernaards, TNO

Work and Employment,

PO Box 718, 2130 AS

Hoofddorp, Netherlands;

C.Bernaards@arbeid.

tno.nl

Accepted 18 May 2005

\begin{abstract}
Aims: To investigate the longitudinal relation between strenuous leisure time physical activity and psychological complaints (depression and emotional exhaustion) in a Dutch working population in order to find evidence for the preventive role of physical activity in the development of psychological complaints. Methods: All data came from the Study on Musculoskeletal disorders, Absenteeism, Stress, and Health (SMASH), a three year follow up study that started between 1994 and 1995. The study population consisted of 1747 workers from 34 companies. Generalised estimating equation (GEE) analyses were performed to investigate the longitudinal relation between strenuous leisure time physical activity and psychological complaints using models with and without a time lag. Logistic regression analyses were performed to study the relation between physical activity and sickness absence due to psychological complaints during the three year follow up study.

Results: Only in workers with a sedentary job was strenuous leisure time physical activity (1-2 times per week) significantly associated with a reduced risk of future depression and emotional exhaustion. This was not the case for physical activity at higher frequencies ( $\geqslant 3$ times per week). There was a dose-response relation between strenuous leisure time physical activity and poor general health which was strongest in workers with a sedentary job. Strenuous leisure time physical activity (1-2 times per week) was associated with a lower risk of long term absenteeism ( $>21$ days), whereas physical activity at a higher frequency was not.

Conclusions: Results suggest that strenuous leisure time physical activity might play a role in the prevention of future psychological complaints, poor general health, and long term absenteeism in a working population. Workers with a sedentary job seem to benefit more from strenuous leisure time physical activity than workers without a sedentary job.
\end{abstract}

$P$ sychological complaints such as general feelings of reduced wellbeing, burnout, anxiety, and depression are an important cause of sickness absenteeism and work disability in the Netherlands. ${ }^{1}$ In 2001 , about $38 \%$ of the new cases of work disability in the Netherlands (that is, about 100000$)$ were psychological in nature. ${ }^{2}$ The total annual costs of work related sickness absence and work disability due to psychological complaints in the Netherlands are estimated at $€ 1444$ million and $€ 1630$ million respectively. ${ }^{3}$

There is evidence for a beneficial effect of physical fitness on mental health, and depression in particular. ${ }^{4-6}$ Several review studies ${ }^{6-8}$ have described physiological and psychological mechanisms to explain the curative role of physical activity with regard to depression. Since depression has multiple aetiologies, it is believed that physiological and psychosocial mechanisms act simultaneously. ${ }^{4}$ Physical activity may lower depression by affecting central monoamine functioning (that is, serotonin, noradrenaline, and dopamine), by lowering the HPA axis response to stress, or by stimulating $\beta$ endorphin levels. On the other hand, physical activity may lower depression by increasing self-esteem, selfefficacy, and feelings of control, by distracting patients from unpleasant stimuli, or by increased social interactions. The largest decreases in depressive symptoms with exercise have been found in clinical and/or medically treated participants, whereas exercise as a treatment for milder forms of depression seems to be successful in some studies ${ }^{9}$ but not in others. ${ }^{10} 11$

Evidence supporting the preventive role of regular physical activity has been less conclusive than evidence supporting the curative role of regular physical activity. ${ }^{6}$ Although several prospective studies have shown that higher amounts of physical activity are associated with reduced depressive symptoms, ${ }^{13-17}$ it is still uncertain whether or not physical activity can prevent depression. Some prospective studies investigated the preventive role of physical activity by stratifying for pre-existing depression in the analyses between physical activity and depression ${ }^{12}$ and found mixed results. As far as we know, no earlier study investigated the longitudinal relation between physical activity and emotional exhaustion, nor the relation between physical activity and sickness absence due to psychological complaints.

The present study was conducted in a cohort of Dutch workers. Psychological complaints included in the present study are depression and emotional exhaustion. We hypothesise that workers with a sedentary job will benefit more from leisure time physical activity than workers without a sedentary job based on previous findings in the same cohort. ${ }^{18}$ These previous findings showed that workers with a sedentary job benefit more from sports participation with regard to sickness absence than workers with a nonsedentary job. The aims of the present study were to:

- Investigate the longitudinal relation between strenuous leisure time physical activity and psychological complaints in a working population, in order to find evidence for the

Abbreviations: CES-D, Center for Epidemiological Studies Depression; $\mathrm{Cl}$, confidence interval; GEE, generalised estimating equation; ICD, International Classification of Diseases; OR, odds ratio; SMASH, Study on Musculoskeletal disorders, Absenteeism, Stress, and Health; SPSS, Statistical Package of Social Sciences 
preventive role of physical activity in the development of psychological complaints

- Investigate the longitudinal relation between strenuous leisure time physical activity and poor general health in a working population

- Investigate the relation between strenuous leisure time physical activity and sickness absence due to psychological complaints in a working population.

\section{METHODS \\ Study population}

All subjects were participants of the Study on Musculoskeletal disorders, Absenteeism, Stress, and Health (SMASH). In this study workers were recruited from 34 companies located throughout the Netherlands. Participating companies were asked to select workers who had been employed in their current job for at least one year and who were working at least 24 hours per week. Workers in bluecollar jobs, as well as workers in white-collar jobs and caring professions were included in the study. For details on the study population and design of the study, see also Hoogendoorn and colleagues. ${ }^{19} 20$ The study was approved by the Medical Ethical Committee of TNO (Leiden, Netherlands). Employees gave their written informed consent to use their sick leave records for the study.

\section{Data collection}

SMASH is a three year follow up study in which baseline measurements were carried out between March 1994 and March 1995 and the follow up measurements in the years 1996, 1997, and 1998. All measurements were separated by one year. At baseline, 1789 (87\%) of the 2064 workers who were invited to participate completed the questionnaire, 1747 of whom were eligible for participation in the present study. Data were collected at baseline and at the three follow up measurements. All outcome variables (that is, depression, emotional exhaustion, and sickness absence due to psychological complaints) were dichotomised.

\section{Depression}

Depression was assessed with help of the Dutch version of the Center for Epidemiological Studies Depression (CES-D) questionnaire, ${ }^{21}{ }^{22}$ which was designed to measure symptoms of depression in community studies. The participant was offered 11 brief statements describing feelings or behaviours and was asked to indicate how often she or he felt that way during the past two weeks (for further details, see de Jonge and colleagues ${ }^{23}$ ). Participants with a score of 6 or higher on the 11 items of the CES-D were classified as being depressed (90th centile).

\section{Emotional exhaustion}

Emotional exhaustion was assessed with one of the three subscales from an adapted Dutch version of the original Maslach Burnout Inventory (MBI-NL). ${ }^{24}$ The scale consisted of seven items, scored on a dichotomous (yes/no) scale (for further details, see de Jonge and colleagues ${ }^{23}$ ). Participants with a score of 4 or higher on the seven item questionnaire were classified as being emotionally exhausted. This cut-off value corresponded to the 90th centile of emotional exhaustion scores.

\section{Poor general health}

Since Dutch workers with psychological complaints often complain about a general feeling of reduced wellbeing, ${ }^{1}$ we investigated the longitudinal relation between strenuous physical activity and poor general health as well. Poor general health was self-reported by using the following single question: "How would you rate your health in general?". Answering categories were good, reasonable, moderate, and bad..$^{25}$ A reasonable, moderate, or bad selfreported health was considered as poor general health.

\section{Strenuous physical activity}

The amount of strenuous physical activity was assessed with the following question: "How often within the past four months did you participate in strenuous sports activities or strenuous physical activities that lasted long enough to become sweaty?". Answering categories were no strenuous physical activity, less than once a month, about once a month, about 2-3 times a month, about 1-2 times a week, 3 times a week or more. ${ }^{26}{ }^{27}$ In the analyses the categories "no strenuous physical activity" and "less than once a month", and the categories "about once a month" and "about 2-3 times a month" were combined to one category. The category "less than once a month" was used as the reference category.

\section{Sedentary job}

The amount of sedentary work was assessed with help of one single question. Participants who reported sitting during the largest part of the working day, were counted as workers with a sedentary job. Participants who did not report sitting during the largest part of the working day were counted as workers with a non-sedentary job.

\section{Sickness absence due to psychological complaints}

Adequate sickness absence data were provided by 21 of the 34 participating companies. A total of $1080(89 \%)$ of the 1213

Table 1 Number of valid observations* and prevalence of depression, emotional exhaustion, and poor general health at baseline and the three follow up measurements

\begin{tabular}{lllll}
\hline & Baseline & Follow up 1 & Follow up 2 & Follow up 3 \\
\hline $\begin{array}{llll}\text { Depression } \\
\text { Valid observations }\end{array}$ & 1653 & 1515 & 1406 & 1401 \\
$\begin{array}{l}\text { Total cases (n) } \\
\text { Prevalence (\%) }\end{array}$ & 151 & 179 & 204 & 221 \\
Emotional exhaustion & 9.1 & 11.8 & 14.5 & 15.8 \\
Valid observations & 1660 & & & \\
Total cases (n) & 84 & 1513 & 1360 & 1404 \\
Prevalence (\%) & 5.1 & 110 & 94 & 89 \\
Poor general health & & 7.3 & 6.9 & 6.3 \\
Valid observations & 1666 & & & \\
Total cases (n) & 335 & 1536 & 1410 & 1405 \\
Prevalence (\%) & 20.1 & 299 & 273 & 301 \\
\hline
\end{tabular}

*With valid data on the outcome variable of interest, gender, sedentary job, and physical activity. 
Table 2 Results from the simple GEE analyses between the frequency of strenuous leisure time physical activity and psychological complaints (depression and emotional exhaustion) and poor general health (all dichotomous)

\begin{tabular}{|c|c|c|c|c|c|c|c|c|}
\hline \multirow[b]{2}{*}{$\begin{array}{l}\text { Frequency of physical } \\
\text { activity }\end{array}$} & \multicolumn{4}{|c|}{ Non-sedentary job } & \multicolumn{4}{|c|}{ Sedentary job } \\
\hline & OR & $95 \% \mathrm{Cl}$ & $\mathrm{p}$ value & $\begin{array}{l}\text { No. of valid } \\
\text { observations (\%) }\end{array}$ & OR & $95 \% \mathrm{Cl}$ & $\mathrm{p}$ value & $\begin{array}{l}\text { No. of valid } \\
\text { observations (\%) }\end{array}$ \\
\hline \multicolumn{9}{|l|}{ Depression } \\
\hline$<1$ per month & 1.00 & - & - & 1220 (34.2) & 1.00 & - & - & $715(29.7)$ \\
\hline $1-3 \times$ per month & 0.99 & $(0.77$ to 1.27$)$ & 0.92 & $887(24.8)$ & 0.73 & $(0.53$ to 1.00$)$ & 0.05 & $583(24.3)$ \\
\hline $1-2 \times$ per week & 0.96 & $(0.74$ to 1.24$)$ & 0.76 & $1023(28.6)$ & 0.64 & $(0.46$ to 0.88$)$ & 0.01 & 801 (33.3) \\
\hline$\geqslant 3 \times$ per week & 0.76 & $(0.55$ to 1.06$)$ & 0.11 & 441 (12.3) & 0.57 & $(0.35$ to 0.94$)$ & 0.03 & 305 (12.7) \\
\hline \multicolumn{9}{|l|}{ Emotional exhaustion } \\
\hline$<1$ per month & 1.00 & - & - & $1204(34.0)$ & 1.00 & - & - & $713(29.7)$ \\
\hline $1-3 \times$ per month & 0.91 & $(0.70$ to 1.19$)$ & 0.50 & $882(24.9)$ & 0.67 & $(0.40$ to 1.10$)$ & 0.12 & $577(24.1)$ \\
\hline $1-2 \times$ per week & $0.70^{*}$ & $(0.51$ to 0.97$)$ & 0.03 & $1014(28.7)$ & 0.48 & $(0.30$ to 0.76$)$ & 0.00 & 801 (33.4) \\
\hline$\geqslant 3 \times$ per week & 0.87 & $(0.54$ to 1.37$)$ & 0.54 & $439(12.4)$ & 0.65 & (0.35 to 1.22 ) & 0.18 & 307 (12.8) \\
\hline \multicolumn{9}{|l|}{ Poor general health } \\
\hline$<1$ per month & 1.00 & - & - & $1232(34.2)$ & 1.00 & - & - & $717(29.7)$ \\
\hline $1-3 \times$ per month & 0.84 & (0.69 to 1.02$)$ & 0.08 & $892(24.8)$ & 0.80 & (0.63 to 1.01$)$ & 0.06 & 584 (24.2) \\
\hline $1-2 \times$ per week & 0.70 & $(0.56$ to 0.86$)$ & 0.00 & $1029(28.6)$ & 0.47 & $(0.36$ to 0.62$)$ & 0.00 & 805 (33.3) \\
\hline$\geqslant 3 \times$ per week & 0.59 & $(0.44$ to 0.79$)$ & 0.00 & 449 (12.5) & 0.42 & $(0.28$ to 0.61$)$ & 0.00 & 309 (12.8) \\
\hline
\end{tabular}

participating workers from these 21 companies had given their informed consent for a follow up based on their sick leave records. If available, reasons for sickness absence were provided and coded according to an adapted Dutch version $^{28}$ of the International Classification of Diseases, version 9 (ICD-9). All diagnoses in Chapter 5 (mental disorders) were considered to constitute sickness absence due to psychological complaints. For the measures of sickness absence the complete follow up period of three years was taken into account. Dichotomous variables were constructed to indicate the three year prevalence of long term sickness absence ( 22 days or more), medium to long term sickness absence ( 8 days or more), and all sickness absence ( 3 days or more).

\section{Statistical analysis}

To study the longitudinal relation between strenuous leisure time physical activity and psychological complaints, we used generalised estimating equation (GEE) analyses ${ }^{29}$ in STATA, since GEE takes into account the time varying nature of both the outcome and the exposure. With GEE analysis, the relation between two longitudinally measured variables can be studied using all longitudinal data simultaneously and adjusting for within person correlations caused by repeated measurement on each subject. ${ }^{30}$ Since both "between subjects associations" and "within subjects associations" are taken into account, the overall regression coefficient from the GEE model is partly based on the cross-sectional relation between physical activity and psychological complaints, and partly based on the relation between changes in physical activity and changes in psychological complaints within each subject. We used two different models to study the longitudinal data, the simple GEE model, and the GEE model with a time lag of one year. The simple GEE model was used to investigate the longitudinal relation between physical activity and current psychological complaints. In this model, we adjusted for time of measurement and gender. The GEE model with time lag was used to investigate the longitudinal relation between physical activity and future psychological complaints. In this model, the independent variable (physical activity) was measured one year prior to the dependent variable (psychological complaints); we adjusted for psychological complaints one year earlier, gender, and time of measurement. The time lag model was used to find evidence for the preventive role of physical activity in the development of psychological complaints.

With the use of GEE analysis, as with proportional hazard modelling, there is a risk for bias when exposure is affected by the study outcome. ${ }^{31}$ This risk is lowest in the time lag model because there is one year between the exposure and the outcome, which makes it less likely that the exposure will be affected by the outcome measure. However, since the exposure might still be affected in case the outcome measure is stable, we adjusted for psychological complaints one year earlier to reduce the risk of bias.

To study the dose-response relation between physical activity and psychological complaints, we used dummy variables for physical activity. This enabled us to compare three physical activity groups (1-3 times per month; 1-2 times per week; and $\geqslant 3$ times per week) with the reference group (strenuous physical activity less than once a month).

To study the relation between physical activity and sickness absence, we used logistic regression analyses from the Statistical Package of Social Sciences (SPSS) and adjusted for gender.

\section{Effect modification}

We investigated possible effect modification by gender and sedentary job by introducing an interaction term to both the GEE models and the logistic regression analyses. Since we found no effect modification by gender $(p<0.10)$, we did not stratify for gender in any of the analyses. Since we found effect modification by sedentary job in the relation between physical activity and depression and in the relation between physical activity and poor self reported general health, we decided to stratify all GEE analyses between physical activity and psychological complaints for sedentary job. We did not stratify the logistic regression analyses on sickness absence to retain sufficient statistical power.

\section{Selective drop-out}

Logistic regression analyses were used to investigate selective drop-out at the first follow up measurement due to depression, emotional exhaustion, or poor general health at baseline. 


\section{RESULTS}

\section{Study population and valid observations}

Table 1 presents the number of participants with valid observations at each measurement, as well as the prevalence of depression, emotional exhaustion, and poor general health at all measurements.

\section{Selective drop-out}

Participants with depression at baseline were at increased risk of dropping out at the first follow up measurement (OR $1.57,95 \%$ CI 1.01 to 2.45 ), as were participants who reported a poor general health at baseline (OR 1.77, 95\% CI 1.27 to 2.46). Emotional exhaustion at baseline did not predict dropout at the first follow up measurement.

\section{Longitudinal relation between strenuous leisure time physical activity and psychological complaints}

The results from the simple GEE model between strenuous leisure time physical activity and psychological complaints are presented in table 2 .

\section{Depression}

We found a dose-response relation between the frequency of strenuous physical activity and depression. The higher the frequency of strenuous physical activity, the lower the risk of depression. Workers with a sedentary job who engaged in strenuous physical activity at least once to twice a week were at a significantly lower risk of depression than those who engaged in strenuous physical activity less than once a month. We found no significant association between strenuous physical activity and a lower risk of depression in workers with a non-sedentary job.

\section{Emotional exhaustion}

All workers who engaged in strenuous physical activity at a frequency of once to twice a week were at a significant lower risk of emotional exhaustion than workers who engaged in strenuous physical activity less than once a month. This association was stronger in workers with a sedentary job. The odds were almost halved on developing emotional exhaustion in workers with a sedentary job who engaged in strenuous physical activity once to twice a week in comparison to workers with a sedentary job who engaged in strenuous physical activity less than once a month.

\section{Poor general health}

We found a dose-response relation between strenuous physical activity and poor general health. The higher the frequency of strenuous physical activity the lower the risk of poor general health. All workers who engaged in physical activity at least once to twice a week were at reduced risk to report poor general health in comparison to workers who engaged in physical activity less than once a month. We found the strongest association between physical activity and poor general health in workers with a sedentary job. Workers with a sedentary job who engaged in strenuous physical activity at least once to twice a week were more than half as likely to report a poor general health compared to workers with a sedentary job who engaged in strenuous physical activity less than once a month.

Table 3 presents the results from the GEE analyses with time lag between the frequency of strenuous leisure time physical activity and future psychological complaints.

\section{Depression}

Workers with a sedentary job who engaged in strenuous physical activity once to twice a week, but not at a higher frequency, were at a reduced risk of future depression (table 3). In contrast, the relation between strenuous physical activity (1-2 times per week) and a reduced risk of future depression was not found in workers with a non-sedentary job.

\section{Emotional exhaustion}

Strenuous physical activity at a frequency of once to twice a week was associated with a lower risk of future emotional exhaustion. As with depression, this effect was only found in workers with a sedentary job. Workers with a sedentary job who engaged in strenuous physical activity once to twice a week were about twice as unlikely to report emotional exhaustion one year later in comparison to those who engaged in strenuous physical activity less than once a month. Although all three physical activity groups showed a reduced risk of future emotional exhaustion in workers with a sedentary job, these findings were non-significant in workers who engaged in leisure time physical activity between one and three times per month and three times per week or more.

\section{Poor general health}

Strenuous physical activity at a frequency of at least once to twice a week was associated with a lower risk of future poor general health in workers with a sedentary job. In workers with a non-sedentary job, on the other hand, strenuous physical activity was only associated with a lower risk of future poor general health at a frequency of at least three times a week.

\section{Strenuous leisure time physical activity and sickness absence due to psychological complaints}

Sickness absenteeism due to psychological complaints was low in our working population. The three year prevalence for absenteeism due to psychological complaints was $13.4 \%$ for total absenteeism (duration 3 days or more), $9.6 \%$ for moderate to long term absenteeism (duration 8 days or more), and $6.3 \%$ for long term absenteeism (duration 22 days or more).

Figure 1 shows that workers who engaged in strenuous physical activity at baseline at a frequency of $1-3$ times a month or 1-2 times a week were at a lower risk of total sickness absence than workers who did not engage in strenuous physical activity $(<1$ per month). The reduced risk of total absenteeism in workers who engaged in strenuous physical activity at a frequency of three times a week or more, on the other hand, was not statistically significant. When only moderate to long term sickness absence was taken into account, we found a reduced risk for all workers who engaged in strenuous physical activity compared to workers who did not engage in strenuous physical activity $(<1$ per month). Nevertheless, this reduced risk was not statistically significant. Finally, we found a doseresponse relation between strenuous physical activity and long term sickness absence. The higher the frequency of strenuous leisure time physical activity at baseline, the lower the risk of long term absenteeism in the next three years. The reduced risk for long term absenteeism was only significant in workers who engaged in leisure time physical activity once to twice a week.

\section{DISCUSSION}

The results of our three year prospective study in a working population show that strenuous "non-supervised" leisure time physical activity is associated with a lower risk of depression, emotional exhaustion, and poor general health. These associations were stronger in workers with a sedentary job than in workers without a sedentary job. Although physical activity at a frequency of once to twice a week was significantly associated with a reduced risk of future 
Table 3 Results from the GEE analyses with a time lag between the frequency of strenuous leisure time physical activity and future psychological complaints (depression and emotional exhaustion) and self-reported poor general health (all dichotomous)

\begin{tabular}{|c|c|c|c|c|c|c|c|c|}
\hline \multirow[b]{2}{*}{ Frequency of physical activity } & \multicolumn{4}{|c|}{ Non-sedentary job } & \multicolumn{4}{|c|}{ Sedentary job } \\
\hline & OR & $95 \% \mathrm{Cl}$ & p value & $\begin{array}{l}\text { No. of valid } \\
\text { observations } \\
(\%)\end{array}$ & OR & $95 \% \mathrm{Cl}$ & p value & $\begin{array}{l}\text { No. of valid } \\
\text { observations (\%) }\end{array}$ \\
\hline \multicolumn{9}{|l|}{ Depression } \\
\hline$<1$ per month & 1.00 & - & - & $806(32.7)$ & 1.00 & - & - & $472(28.1)$ \\
\hline $1-3 \times$ per month & 0.91 & $(0.64$ to 1.29$)$ & 0.59 & $607(24.6)$ & 0.83 & $(0.58$ to 1.20$)$ & 0.33 & $420(25.0)$ \\
\hline $1-2 \times$ per week & 0.84 & $(0.62$ to 1.14$)$ & 0.27 & $731(29.6)$ & 0.62 & $(0.43$ to 0.91$)$ & 0.01 & $569(33.9)$ \\
\hline$\geqslant 3 \times$ per week & 0.80 & $(0.53$ to 1.21$)$ & 0.29 & $322(13.1)$ & 0.83 & $(0.50$ to 1.37$)$ & 0.46 & $219(13.0)$ \\
\hline \multicolumn{9}{|l|}{ Emotional exhaustion } \\
\hline$<1$ per month & 1.00 & - & - & $771(32.3)$ & 1.00 & - & - & $455(27.7)$ \\
\hline $1-3 \times$ per month & 0.88 & (0.59 to 1.32$)$ & 0.54 & $595(24.9)$ & 0.53 & (0.28 to 1.01$)$ & 0.05 & $405(24.7)$ \\
\hline $1-2 \times$ per week & 0.78 & $(0.51$ to 1.20$)$ & 0.26 & $706(29.6)$ & 0.46 & $(0.26$ to 0.82$)$ & 0.01 & $565(34.5)$ \\
\hline$\geqslant 3 \times$ per week & 1.10 & $(0.68$ to 1.79$)$ & 0.69 & $316(13.2)$ & 0.50 & $(0.25$ to 1.01$)$ & 0.05 & $215(13.1)$ \\
\hline \multicolumn{9}{|l|}{ Poor general health } \\
\hline$<1$ per month & 1.00 & - & - & $820(32.8)$ & 1.00 & - & - & $473(27.9)$ \\
\hline $1-3 \times$ per month & 0.95 & (0.70 to 1.29 ) & 0.74 & $614(24.5)$ & 0.85 & (0.59 to 1.21$)$ & 0.36 & $421(24.9)$ \\
\hline $1-2 \times$ per week & 0.83 & $(0.62$ to 1.11$)$ & 0.22 & $737(29.4)$ & 0.52 & $(0.36$ to 0.75$)$ & 0.00 & $577(34.1)$ \\
\hline$\geqslant 3 \times$ per week & 0.63 & $(0.42$ to 0.95$)$ & 0.03 & $332(13.3)$ & 0.39 & $(0.23$ to 0.66$)$ & 0.00 & $222(13.1)$ \\
\hline
\end{tabular}

Reference group: physical activity less than once a month.

Adjusted for time of measurement, outcome measurement one year earlier, and gender.

depression and emotional exhaustion, this was not the case for physical activity at a higher frequency. Similarly, physical activity at a frequency one to twice a week was associated with a lower risk of long term absenteeism whereas physical activity at a higher frequency was not. These results suggest that strenuous leisure time physical activity might play a role in the prevention of future psychological complaints, poor general health, and long term absenteeism in a working population. To our knowledge, this is the first study that investigates the role of leisure time physical activity in the prevention of emotional exhaustion and work absenteeism due to psychological complaints in a working population.

Our results regarding the preventive role of physical activity in the development of depression are in agreement

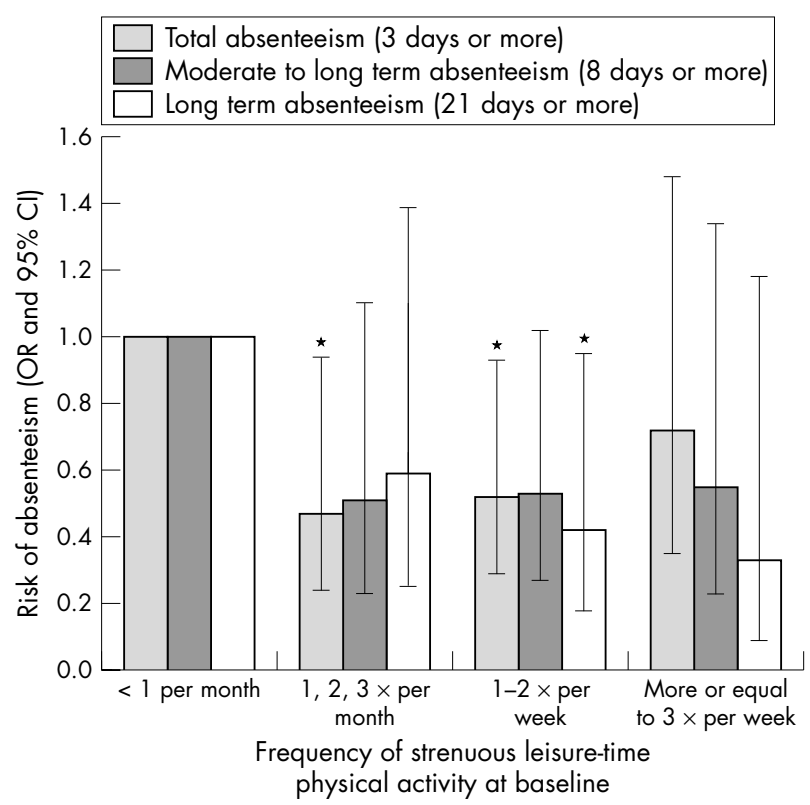

Figure 1 Strenuous leisure time physical activity at baseline and the risk of total absenteeism, moderate to long term absenteeism, and long term absenteeism in the next three years. ${ }^{*} p<0.05$. Odds ratios are adjusted for gender. with some prior longitudinal studies ${ }^{12-14}$ and in disagreement with others. ${ }^{16}$ In an eight year follow up study, Farmer and colleagues $^{12}$ found that little or no recreational physical activity predicted depressive symptoms at follow up in white women but not in white men, although the cross-sectional analyses between physical activity and depressive symptoms showed a significant relation in both sexes. Another follow up study ${ }^{13}$ showed that low active non-depressed subjects were at a significantly larger risk of depression nine years later compared to high active non-depressed subjects. Even more interesting was their result that participants who increased their physical activity during follow up, were at similar risk of depression than those who were active from the beginning. Participants who decreased physical activity during follow up, on the other hand, were at increased risk of depression compared to those who remained active. Paffenbarger and colleagues ${ }^{14}$ found that men with a high physical activity index (that is, high weighted metabolic score) and men who engaged in sports were at a lower risk of developing clinical depression during the 23 or 27 year follow up than less active men. Our results differ from the results presented by Cooper-Patrick and colleagues, ${ }^{16}$ who found no significant relation between physical activity and lower clinical depression and psychological distress in midlife.

When comparing our results with the results from previous prospective studies, we should be aware of the different methods used to measure depression and the different definitions used for physical activity. In a similar manner to Farmer and colleagues, ${ }^{12}$ we assessed depression with help of the CES-D questionnaire. ${ }^{20}$ Since the CES-D questionnaire is designed to measure symptoms of depression in community studies, our population differs from studies that used clinical depression based on medical records. ${ }^{14}{ }^{16}$ Our definition of physical activity is comparable to the definition used by Cooper-Patrick and colleagues, ${ }^{16}$ but differs from the definition used by others. ${ }^{12}{ }^{14}$ Farmer and colleagues ${ }^{12}$ did not take intensity of physical activity into account but discriminated between recreational physical activity and non-recreational physical activity. Paffenbarger and colleagues ${ }^{14}$ discriminated between intensity and frequency (hours per week) of playing sports, and studied several forms of physical activity (for example, walking, stair climbing, playing sports). Since different categories of physical activity (strenuous physical 


\section{Main messages}

- Strenuous leisure time physical activity is associated with a lower risk of depression, emotional exhaustion, and poor general health in a working population.

- The associations between strenuous physical activity and psychological complaints were stronger in workers with a sedentary job than in workers without a sedentary job.

- Strenuous physical activity at a frequency of once to twice a week was associated with a lower risk of long term absenteeism, whereas physical activity at a higher frequency was not.

- The results of our study suggest that strenuous leisure time physical activity might play a role in the prevention of future psychological complaints, poor general health, and long term absenteeism in a working population.

activity versus light physical activity, and group activities versus individual activities) might act on psychological complaints through other mechanisms, our results are difficult to compare with the results from previous studies.

To our surprise, we found that workers who engaged in strenuous physical activity once to twice per week were at a lower risk of developing depression and emotional exhaustion than workers who engaged in strenuous physical activity at higher frequencies. Although our high frequency physical activity group was slightly younger and higher educated in comparison to the other physical activity groups, additional adjustment for age and educational level did not change our findings (data not shown). Future research should investigate the preventive effect of different forms of physical activity, and the effect of intensity, frequency, and combinations of intensity and frequency (for example, low intensityhigh frequency, high intensity-low frequency).

\section{Confounders}

In the study of Camacho and colleagues, ${ }^{13}$ covariates such as smoking status, alcohol consumption, and physical health explained part of the association between physical activity and depression. Since smoking status and alcohol consumption were available in our dataset, we ran additional simple GEE analyses with adjustment for smoking status and alcohol consumption. Neither the adjustment for alcohol consumption nor the adjustment for smoking status changed the conclusions of our study (data not shown).

\section{Selection bias}

It is likely that we underestimated the association between strenuous physical activity and poor general health. Workers who reported a poor general health at baseline were at increased risk of drop-out at the first follow up measurement, and were also at increased risk to report physical inactivity (that is, frequency of strenuous physical activity less than once a month) at baseline. Workers with depression at baseline were at increased risk to drop-out at the first follow up measurement as well, but they were not at increased risk to report physical inactivity in comparison to workers without depression at baseline.

\section{Limitations}

Firstly, we used a longitudinal design that does not allow us to draw firm conclusions on causality. However, by comparing the results from a simple GEE model with the results

\section{Policy implications}

- Given the many health benefits that are associated with physical activity, companies should consider the promotion of physical activity, despite the fact that its effectiveness in preventing psychological complaints still needs to be confirmed by high quality randomised controlled trials.

from a GEE model with time lag and adjustment for psychological complaints at baseline, we tried to gain more insight into the preventive effect of physical activity. Whereas the results from the simple GEE model will partly be explained by the cross-sectional association between physical activity and psychological complaints (that is, workers with psychological complaints and a poor general health are less inclined to be physically active than people without psychological complaints and a good general health), the results from the GEE model with time lag will reflect the preventive effect of physical activity more strongly. The results from both models clearly point in the same direction, suggesting that psychological complaints can be predicted by both current and previous physical activity.

Secondly, we dichotomised psychological complaints. A change in depression score from 5 to 6 , for instance, is translated as a change from no depression to depression, whereas a change in depression score from 0 to 4 is not. The score on depression could not be expressed a continuous variable since the distribution of depression was highly skewed, with a high number of workers scoring zero.

Thirdly, we did not take into account when absences occurred during the three years of follow up. As a consequence, the results should be interpreted with caution. Finally, since reasons for sickness absence were provided for only 606 cases, our results regarding the relation between strenuous leisure time physical activity and absenteeism are based on a relatively low number of participants. This could explain why some of the are results are not significant.

\section{Future studies}

Future intervention studies should confirm the effectiveness of physical activity in the prevention of depression and emotional exhaustion in a working population. So far, the scientific evidence on the effectiveness of physical activity programmes at worksites is still limited due to few high quality randomised controlled trials. ${ }^{32}$ One study investigated the effect of physical exercise on self-reported job stress, sick leave, and health complaints and found no significant effect. ${ }^{33}$ More randomised controlled trials of high quality are needed to investigate the effectiveness of physical activity programmes at the worksite on the prevention and reduction of mild psychological complaints.

\section{Conclusions}

The longitudinal relation between strenuous leisure time physical activity and the lower risk of future psychological complaints and poor general health suggest that strenuous leisure time physical activity might play a role in the prevention of future psychological complaints and poor general health in a working population. The association between strenuous leisure time physical activity (1-2 times per week) and the reduced risk of long term absenteeism ( $>21$ days) further suggests that strenuous leisure time physical activity might also play a role in the prevention of long term absenteeism. Workers with a sedentary job seem to 
benefit more from strenuous leisure time physical activity than workers without a sedentary job.

\section{Authors' affiliations}

C M Bernaards, Body@Work, Research Center Physical activity, Work and Health, TNO-VU University Medical Center, Netherlands and TNO Work and Employment, Hoofddorp, Netherlands

M P Jans, S G van den Heuvel, I J Hendriksen, I L Houtman, TNO Work and Employment, Hoofddorp, Netherlands

P M Bongers, TNO Work and Employment, Hoofddorp, Netherlands and Body@Work, Research Center Physical activity, Work and Health, TNO-VU University Medical Center, Netherlands

Funding: The original SMASH study was funded by the Dutch Ministry of Social Affairs and Employment. The analyses for this report were funded by the Dutch Ministry of Health, Welfare and Sport.

Competing interests: none

\section{REFERENCES}

1 Houtman ILD, Schoenmaker CG, Blatter BM, et al. Psychological complaints, interventions and return to work. The prognosis study INVENT [in Dutch]. Hoofddorp: TNO Work and Employment, 2002.

2 Houtman I, Andries F, Hupkens C. Core figures on health, productivity and social security. In: Houtman ILD, Smulders PGW, Klein Hesselink DJ, eds. Trends in Work [in Dutch]. Hoofddorp: TNO Work and Employment, 2004

3 Koningsveld EAP, Zwinkels WS, Mossink JCM, et al. Costs for society due to working conditions of employees in 2001 [in Dutch]. Hoofddorp: TNO Work and Employment, 2003.

4 Dunn AL, Trivedi MH, O'Neal HA. Physical activity dose-response effects on outcomes of depression and anxiety. Med Sci Sports Exerc 2001;33(suppl):S587-97.

5 Lawlor DA, Hopker SW. The effectiveness of exercise as an intervention in the management of depression: systematic review and meta-regression analysis of randomised controlled trials. BMJ 2001;322:763-7.

6 Brosse AL, Sheets ES, Lett HS, et al. Exercise and the treatment of clinical depression in adults. Recent findings and future directions. Sports Med 2002:32:741-60.

7 Paluska SA, Schwenk TL. Physical activity and mental health. Sports Med 2000;29:167-80.

8 Salmon P. Effects of physical exercise on anxiety, depression, and sensitivity to stress: a unifying theory. Clin Psychol Rev 2001;21:33-61.

9 Andersen RE, Wadden TA, Bartlett SJ, et al. Effects of lifestyle activity vs structured aerobic exercise in obese women: a randomized trial. JAMA 1999;281:335-40.

10 King AC, Taylor CB, Haskell WL, et al. Influence of regular aerobic exercise on psychological health: a randomized, controlled trial of healthy middle-aged adults. Health Psychol 1989;8:305-24.

11 Cramer SR, Nieman DC, Lee JW. The effects of moderate exercise training on psychological well-being and mood state in women. J Psychosom Res 1991;35:437-49.
12 Farmer ME, Locke BZ, Moscicki EK, et al. Physical activity and depressive symptoms: the NHANES-1 epidemiologic follow-up study. Am J Epidemiol 1988;128:1340-51.

13 Camacho TC, Roberts RE, Lazarus NB, et al. Physical activity and depression: evidence from the Alameda County study. Am J Epidemiol $1991 ; 134: 220-31$

14 Paffenbarger Jr RS, Lee IM, Leung R. Physical activity and personal characteristics associated with depression and suicide in American college men. Acta Psychiatr Scand Suppl 1994;377:16-22.

15 Mobily KE, Rubenstein LM, Lemke JH, et al. Walking and depression in a cohort of older adults: the lowa 65+ Rural Health Study. J Aging Phys Act 1996;4:119-35.

16 Cooper-Patrick L, Ford DE, Mead LA, et al. Exercise and depression in midlife: a prospective study. Am J Public Health 1997:87:670-3.

17 Morgan K, Bath PA. Customary physical activity and psychological wellbeing: a longitudinal study. Age Ageing 1998;27:35-40

18 Van den Heuvel SG, Boshuizen HC, Hildebrandt VH, et al. Effect of sporting activity on absenteeism in a working population. $\mathrm{Br} /$ Sports Med 2005;39:e15.

19 Hoogendoorn WE, Bongers PM, de Vet HCW, et al. Flexion and rotation of the trunk and lifting at work are risk factors for low back pain. Spine 2000;25:3087-92.

20 Hoogendoorn WE, Bongers PM, de Vet HCW, et al. High physical work load and low job satisfaction increase the risk of sickness absence due to low back pain: results of a prospective cohort study. Occup Environ Med 2002;59:323-8.

21 Radloff LS. The CES-D Scale: a self-reported depression scale for research in the general population. Applied Psychol Measur 1977;1:385-401.

22 Kohout FJ, Berkman LF, Evans DA, et al. Two shorter forms of the CESD-D Depression Symptoms Index. J Aging Health 1993;5:179-93.

23 de Jonge J, Reuvers MM, Houtman IL, et al. Linear and nonlinear relations between psychosocial job characteristics, subjective outcomes, and sickness absence: baseline results from SMASH. J Occup Health Psychol 2000;5:256-68.

24 Schaufeli WB, Dierendonck $D$ van. The construct validity of two burnout measures. J Organ Behav 1993;14:631-47.

25 Koeters MWJ, Ormel J. Handleiding General Health Questionnaire. Lisse: Swets en Zeitlinger, 1991

26 Godin G, Jobin J, Bouillon J. Assessment of leisure time exercise behavior by self-report: a concurrent validity study. Can J Public Health 1986;77:359-62.

27 Gionet NJ, Godin G. Self-reported exercise behavior of employees: a validity study. J Occup Med 1989:31:969-73.

28 GAK. Differentiated diagnosis code system [in Dutch]. Amsterdam: GAK, 1990

29 Liang K-Y, Zeger SL. Longitudinal data analysis using generalized linear models. Biometrika 1986;73:13-22.

30 Twisk JW, Kemper HC, Mellenbergh DJ, et al. Factors influencing tracking of cholesterol and high-density lipoprotein: the Amsterdam Growth and Health Study. Prev Med 1996;25:355-64.

31 Rothman KJ, Greenland S. Modern epidemiology, 2nd edn. Philadelphia, PA: Lippincott-Raven, 1998:422.

32 Proper KI, Staal BJ, Hildebrandt VH, et al. Effectiveness of physical activity programs at worksites with respect to work-related outcomes. Scand J Work Environ Health 2002;28:75-84.

33 Eriksen HR, Ihlebæk C, Mikkelsen A, et al. Improving subjective health at the worksite: a randomised controlled trial of stress management training, physical exercise and an integrated health programme. Occup Med 2002;52:383-91. pages 73-78

(1) $a ;(2) d ;(3) b ;(4) c ;(5) b$ 